\title{
The Darkroom is Closed. Introducing Digital Image Ethics to a New Generation.
}

\author{
D. W. Cromey
}

Cell Biology \& Anatomy, University of Arizona, 1501 N. Campbell Ave., Tucson, AZ, 85724-5044

The first time many of us saw a photographic darkroom, we entered into a place full of interesting equipment and smells, all lit with a dim colored light. To successfully create negatives and prints, we were taught about proper exposures, chemical temperatures, different grades of paper, and probably a few tricks like dodging and burning. Most of today's students have never used an enlarger. Their darkroom is found in programs like Adobe Photoshop ${ }^{\mathrm{TM}}$. Unfortunately, it seems rare that these students know much about the proper way to work with digital images. As microscopic imaging becomes digital, it is up to faculty mentors and facility managers to be deliberate in teaching a new generation how to correctly work with digital images.

Prior to the year 2000, very little was said in the scientific press about digital image ethics. There were a few news stories about allegations of misconduct [1], but during that time even the journals were struggling with making the transition from photographic to digital images [2]. In the last seven years, the most prominent voice calling for change in the way image manipulations are reported has been the Journal of Cell Biology's Dr. Michael Rossner [3]. One of the earliest societies to take a stand on this issue, the Microscopy Society of America, published their official position on ethical digital imaging in 2003 [4].

Given the growing concern in the scientific community about digital image manipulation ethics, how extensive is the problem? At its worst, image manipulation can be used to commit scientific fraud. The U.S. Office of Research Integrity investigates misconduct allegations that involve funds from agencies such as the NIH, PHS, CDC, and FDA. The ORI defines research misconduct as "fabrication, falsification, or plagiarism in proposing, performing, or reviewing research, or in reporting research results" [5]. Over the last decade, the ORI has seen the percentage of cases that include questioned images increase from approximately 5\% fifteen years ago to over 50\% in 2007-8 [6].

The ORI often sees the more egregious misconduct cases, but how bad is the problem with inappropriate image manipulation elsewhere? In 2002, the Journal of Cell Biology hired a special editor whose job was to screen reviewed and accepted articles for image manipulations that violated the journal's instructions to authors [3]. Since that time, the JCB has identified 250 papers with questionable images. Twenty-five of these were rejected because the manipulations affected the interpretation of the data [7]. Where do these rejected papers go? At least twice Dr. Rossner has seen a paper that was rejected by the JCB published in a different journal [8]. A survey conducted by the American Journal of Respiratory Cell and Critical Care Medicine found that in accepted manuscripts, approximately $23 \%$ of the images had undergone some alteration [9].

While the incidence of fraudulent images is rare, inappropriate image manipulation is an on-going problem that needs to be addressed by the scientific community. An analysis of recent ORI misconduct cases (of all types) suggests that, to avoid trainee misconduct, mentors need to play a more active role in supervising their trainees [10]. The key suggestions of this paper were that 
mentors should: regularly review the original source data with their trainees, teach specific research standards for working with scientific data, and be aware that overwhelmed/stressed trainees can make unwise decisions.

At the University of Arizona three microscopy facility managers and a professional photographer have banded together to teach specific digital image research standards by putting on a twice yearly workshop entitled "Introduction to Scientific Digital Imaging" [11]. This half-day workshop introduces members of the campus community to basic digital image concepts such as: pixels, voxels, bit depth, color, CCD cameras, noise, sampling, digital filters, file formats, monitor calibration, and data presentation. In addition to the lectures, these concepts, as well as common image processing pitfalls, are demonstrated with images using Adobe Photoshop ${ }^{\mathrm{TM}}$. A twelve point list of guidelines for the proper acquisition and manipulation of scientific digital images [12] is presented at the workshop, with each presenter intentionally reiterating several of the guidelines. The goal is to impress upon the attendees that scientific digital imaging is not as simple as they may have thought, and that great care must be taken when working with digital image data. After the workshop the presenters make themselves available as a resource to the campus community.

The twelve guidelines are available to the microscopy community as a training tool at the "Online Learning Tool for Research Integrity and Image Processing” [13]. The site explains the rationale behind each of the specific guidelines in an outline format. The website includes videos illustrating the guidelines, a dramatized case study, and an interview with Dale Benos, Ph.D., formerly the Editor-in-Chief for the American Journal of Physiology: Cell Physiology.

The continuing problem of inappropriately manipulated images $[3,6,7,8,9]$ indicates that a greater effort must be made to educate the scientific community. MSA members should take up the challenge to teach their colleagues, and especially their trainees, about appropriate ways to work with digital images. [14]

[1] Cromey, D.W., J. Sci. Eng. Ethics (2009, in press).

[2] Rossner, M.T., et al., CBE Views 21(6) (1998) 187-192.

[3] Rossner, M. \& Yamada, K.M., J Cell Biol. 166(1) (2004) 11-15.

[4] Microscopy Society of America, Microscopy Today (Nov/Dec 2003) p61.

[5] Definition of Research Misconduct, U.S. Dept. of Health and Human Services, Office of

Research Integrity, http://ori.dhhs.gov/misconduct/definition_misconduct.shtml

[6] Krueger, J., presentation given to the National Press Club, Washington, DC (4/17/2008).

[7] Young, J.R., The Chronicle of Higher Education (June 8, 2008) A1, A10-11.

[8] Cook, G., (1/11/2006) Boston Globe.

[9] Abraham, E., et al., Proc Am Thoracic Soc 5 (2008) 869.

[10] Wright, D.E., et al., J. Sci. Eng. Ethics 14 (2008) 323-336.

[11] Carl Boswell, Ph.D., Charles Hedgecock, David Elliott, Ph.D., and Douglas Cromey, M.S. [12] Cromey, D.W., (2001, modified in 2004, 2006) Digital Imaging: Ethics, http://swehsc.pharmacy.arizona.edu/exppath/micro/digimage ethics.php

[13] Vollmer, S. \& Kincaid, H., Univ. of Alabama - Birmingham; Guidelines and case study contributing author: D. Cromey, Univ. of Arizona. (2008)

http://www.uab.edu/researchintegrityandimages (Funded by ORI)

[14] Mr. Cromey is supported, in part, by the SWEHSC (NIEHS ES006694). 